Tropical Journal of Pharmaceutical Research April 2017; 16 (4): 755-760

ISSN: $1596-5996$ (print); 1596-9827 (electronic)

(C) Pharmacotherapy Group, Faculty of Pharmacy, University of Benin, Benin City, 300001 Nigeria.

All rights reserved.

Available online at http://www.tjpr.org

Original Research Article

http://dx.doi.org/10.4314/tjpr.v16i4.3

\title{
Label-free biochips for rapid detection of soybean allergen GlymBd 30K (P34) in foods
}

\author{
Wei Wang ${ }^{1 \star}$, Xudong Zhu ${ }^{2}$, Shuang Teng ${ }^{1}$, Qiaojun Fan ${ }^{1}$ and Hang Qian ${ }^{1}$ \\ ${ }^{1}$ Key Laboratory of Meat Processing and Quality Control, Ministry of Education, ${ }^{2}$ College of Sciences, Nanjing Agricultural \\ University, Nanjing 210095, PR China
}

*For correspondence: Email: wangwei821220@njau.edu.cn; Tel/Fax: +86-025-84395650

Revised accepted: 20 March 2017

\begin{abstract}
Purpose: To develop an innovative method for detection of soybean allergen, Gly mBd 30K (P34) in foods using a biosensor based on high spatial imaging ellipsometer.

Methods: Two monoclonal antibodies, 2D1 and 5F9, each known to have specific bioactivity against P34 allergen, were selected and separately immobilized as ligands on silicon wafer surface to allow capture of the P34 allergen. The resultant changes on the wafer surface were viewed directly as images in gray scale.

Results: Images indicated that these two antibodies detected the presence of P34 allergen in soybean extract with sensitivity of $1 \mathrm{mg} / \mathrm{L}$ and a detection time of about $15 \mathrm{~min}$. For the detection of P34 allergen in foods, results from biochip detection were consistent with those obtained using ELISA detection. Conclusion: These results show that the biochip may be an effective analytical tool for food allergen detection.
\end{abstract}

Keywords: Soybean Allergen, Gly mBd 30K, Biochip, Detection, Foods

Tropical Journal of Pharmaceutical Research is indexed by Science Citation Index (SciSearch), Scopus, International Pharmaceutical Abstract, Chemical Abstracts, Embase, Index Copernicus, EBSCO, African Index Medicus, JournalSeek, Journal Citation Reports/Science Edition, Directory of Open Access Journals (DOAJ), African Journal Online, Bioline International, Open-J-Gate and Pharmacy Abstracts

\section{INTRODUCTION}

Soybean allergy is extremely important because soybeans are widely used in numerous food products and contain a particularly insidious hidden allergen [1]. Nearly $0.5 \%$ of the general population and $3-6 \%$ of children are affected by soybean allergy. Clinical symptoms of soybean allergy range from severe enterocolitis to atopic eczema and immediate, multi-system IgEmediated reactions [2]. Among the allergenic soybean proteins determined to date, Gly $\mathrm{mBd}$ $30 \mathrm{~K}$ (P34) is a major allergen. This $30-34 \mathrm{kDa}$ protein is a low-level but highly conserved seed storage protein [3]. P34 is widespread in wild and cultivated soybeans. More than $65 \%$ of soybean-allergic patients react only to the P34 protein $[4,5]$. Thus, appropriate analytical methods are necessary for monitoring the presence of this allergen in foodstuffs and ensuring that proper labeling requirements are being followed. To date, enzyme-linked immunosorbent assay (ELISA) and polymerase chain reaction (PCR) have been reported and are commonly used for food allergen detection, and they have been adopted as standard methods of choice by food industries and food safety regulatory authorities [6,7]. However, these techniques are limited by the need for tracer labeling, indirect identification, and lengthy detection times. Biochip based on imaging ellipsometry, as a non-destructive and label-free technique for thin layer analysis [8], is so sensitive that it can achieve resolution for film thickness in the sub-nanometer region [9]. Previous studies have reported that it can be used in many different biomedical fields such as 
biomolecular interactions, viral examinations, and biomarker measurements [10-13].

In the present study, we describe a biochip detection technology for P34 allergen in food products. Two monoclonal antibodies (mAbs) were selected against the P34 allergen, and then immobilized as silicon-surface ligands. The accuracy, sensitivity, and specificity of biochips in detecting the P34 allergen were then determined.

\section{EXPERIMENTAL}

\section{Materials and reagents}

Silicon wafers were obtained from the General Research Institute for Non-ferrous Metals in Beijing, China. Fast Soya ELISA kit was purchased from R-Biopharm (Germany); 3aminopropyltriethoxy-silane (APTES, $99 \%$, v/v) was product of ACROS (Geel, Belgium), while sulfuric acid $\left(\mathrm{H}_{2} \mathrm{SO}_{4}, 98 \%\right)$, hydrogen peroxide $\left(\mathrm{H}_{2} \mathrm{O}_{2}, 30 \%\right)$ and absolute ethanol $(99.7 \%)$ were purchased from Nanjing Chemical Reagent Co., Ltd. (Nanjing, China). 1-(3-dimethylaminopropyl)-3-ethylcarbodiimide hydrochloride (EDC), N-hydroxysuccinimide (NHS); glycine (Gly), succinic anhydride, bovine serum albumin (BSA), and Tween 20 were obtained from SigmaAldrich (USA). P34 standard sample, two specific mouse IgG1 mAbs against P34 (2D1 and 5F9) were provided by Shenzhen University Medical College in Shenzhen, China.

Phosphate-buffered saline (PBS, composition: $140 \mathrm{mmol} / \mathrm{L} \mathrm{NaCl}, 2.7 \mathrm{mmol} / \mathrm{L} \mathrm{KCl}, 10 \mathrm{mmol} / \mathrm{L}$ $\mathrm{Na}_{2} \mathrm{HPO} 4,1.8 \mathrm{mmol} / \mathrm{L} \mathrm{KH}_{2} \mathrm{PO} 4, \mathrm{pH}$ 7.3) and PBST (PBS with $1 \%$ Tween 20) was prepared in de-ionized water $(18.3 \mathrm{M} \Omega \mathrm{cm})$ obtained from a Milli-Q Plus system (Millipore Corporation, Billerica, MA, USA). Samples of soybean, soybean milk powder, cream cake, cereal bar, chocolate biscuits, pineapple cake, egg, dried milk, shrimp, fish, peanut, wheat, and graham bread were obtained from local markets in Nanjing, China. Two mAbs against the P34 allergen were diluted to $0.1 \mathrm{mg} / \mathrm{mL}$ with PBST. The blocking reagents were combined by dissolving $10 \mathrm{mg} \mathrm{BSA}$ and $10 \mathrm{mg}$ Gly in $100 \mathrm{~mL}$ of PBS.

\section{Allergen extraction}

Crude P34 allergen was extracted from the samples in accordance with the procedure described by Qiao [14], with slight modifications. Thirty grams of each sample was homogenized in an IKA®A11 basic (IKA, Germany) with $30 \mathrm{~mL}$ of egg white in $100 \mathrm{~mL}$ of PBS (pH 7.4), and the homogenate was stirred for $15 \mathrm{~min}$ at $60^{\circ} \mathrm{C}$.
Insoluble resides were removed by centrifugation for $5 \mathrm{~min}$ at $3000 \mathrm{~g}$. Then, the supernatant was collected and centrifuged again for $5 \mathrm{~min}$ at $20,000 \mathrm{~g}$. The resultant supernatant was kept at $20{ }^{\circ} \mathrm{C}$ prior to use. Proteins in all commercial samples were prepared in a similar manner.

\section{Surface modification of silicon wafer}

Silicon wafers were cut into $2 \mathrm{~cm} \times 1.5 \mathrm{~cm}$ section and rinsed with de-ionized water. The wafer surfaces were washed for $30 \mathrm{~min}$ in a solution containing $1: 3$ volume ratio of $30 \% \mathrm{H}_{2} \mathrm{O}_{2}$ and $98 \% \mathrm{H}_{2} \mathrm{SO}_{4}$. This procedure enriched the wafer surface with silanol groups. After rinsing with de-ionized water, the wafers were incubated for $2 \mathrm{~h}$ in a 1:10 volume ratio of APTES and absolute ethanol. The reaction of APTES with the silanol groups on the surface resulted in covalent immobilization of $-\mathrm{O}-\mathrm{Si}(\mathrm{OH})_{2}-\left(\mathrm{CH}_{2}\right)_{3}-$ $\mathrm{NH}_{2}$, thereby generating densely-packed amino groups on the surface. After rinsing with absolute ethanol, the wafers were immersed for $12 \mathrm{~h}$ in a saturated solution of succinic anhydride in absolute ethanol. The $-\mathrm{CH}_{2} \mathrm{CH}_{2} \mathrm{COOCO}$ - group of succinic anhydride reacted with $-\mathrm{O}-\mathrm{Si}(\mathrm{OH})_{2}-$ $\left(\mathrm{CH}_{2}\right)_{3}-\mathrm{NH}_{2}$ immobilized on the surface, forming$\left(\mathrm{CH}_{2}\right)_{3} \mathrm{NH}-\mathrm{CO}\left(\mathrm{CH}_{2}\right)_{2}-\mathrm{COOH}$. The processed wafers were kept in absolute ethanol until used.

\section{Ligand immobilization and P34 allergen detection}

When the modified wafers were put into a microfluidic device [15], the carboxyl groupson their surface were activated by EDC/NHS (consisting of $0.05 \mathrm{~mol} / \mathrm{L} \mathrm{NHS}$ and $0.2 \mathrm{~mol} / \mathrm{L}$ EDC in de-ionized water at a concentration of 10 $\mu \mathrm{L}$ per unit, and allowed to flow through the surface at a concentration of a $5 \mu \mathrm{L} / \mathrm{min}$ ). The carboxyl groups were changed to sulfo-NHS ester by EDC/NHS, when they reacted with the amine groups of the protein. Subsequently, the two mAbs (2D1 and 5F9) were injected into each cell $(10 \mu \mathrm{L}$ per unit at $1 \mu \mathrm{L} / \mathrm{min})$ and immobilized separately as ligands in the microarray using the microfluidic device. Finally, the surface of each unit in the microarray was blocked in the blocking solution $(40 \mu \mathrm{L}$ per unit at $1 \mu \mathrm{L} / \mathrm{min})$. The units were washed with PBST $(15 \mu \mathrm{L}$ per unit at 5 $\mu \mathrm{L} / \mathrm{min}$ ) in-between procedures. Thus, a specific microarray with a sensing surface array was prepared. P34 allergen protein or soybean samples were brought into contact with the sensing surface. In the first place, P34 allergen was recognized by specific ligands when it flowed over the sensing surface $(10 \mu \mathrm{L}$ per unit at $1 \mu \mathrm{L} / \mathrm{min})$. Subsequently, the wafer was washed with de-ionized water $(15 \mu \mathrm{L}$ per unit at 5 $\mu \mathrm{L} / \mathrm{min}$ ), and the microarray was taken out from 
the microfluidic device. After rinsing with much de-ionized water and drying under nitrogen, the results were determined by images in gray scale. The capture of the P34 allergen brought about an increase in the gray scale value for each corresponding unit. The gray scale images and gray scale values were obtained using the Ellipsometric Imaging System (SE 400, SENTECH, Germany).

\section{Determination of sensitivity}

To determine the sensitivity of biochips for the detection of P34 allergens, soybean allergen P34 was prepared by serial dilution using PBST to obtain concentrations of $25,12.5,6.25,3.125$ and $1 \mathrm{mg} / \mathrm{mL}$. Protein concentration was quantified using the Bradford assay. The concentration gradient of the P34 allergen was then obtained from measurement of different gray scale values. These results were acquired from four replicates at each concentration.

\section{Detection of P34 allergen in commercial foods}

To verify the specificity and accuracy of our analysis, soybean and soybean milk powder were chosen as positive controls, while egg, milk, shrimp, fish, peanut, wheat, and graham bread served as negative controls. Manufactured foods such as cream cake, cereal bar, chocolate biscuits, and pineapple cake were screened for presence of P34 allergen. P34 allergens from the commercial foods and proteins from the negative controls were prepared using the method of Qiao as described earlier [14]. The extracts were diluted in a volume ratio of 1:10 with PBST and tested in four replicates.

\section{Detection of soybean allergen using ELISA kit}

Protein extraction and immunochemical detection of soybean allergen was done in three replicates using commercial FAST Soya kit in accordance with the instructions in the kit manual.

\section{Statistics}

Analyses of variance (ANOVA) were carried out using Microcal Origin 8.0 (Microcal Software, Inc., Northampton, MA, USA). Data are presented as mean \pm SD. The significance level was sey at $p<0.05$.

\section{RESULTS}

\section{Qualitative detection of P34 allergen}

The detectable signals of soybean allergen extracts were brighter than those of the blank control and other samples (egg, milk, shrimp, fish, peanut, and wheat; Figure 1A). Furthermore, the interactions between the soybean allergen P34 and two mAbs (2D1and

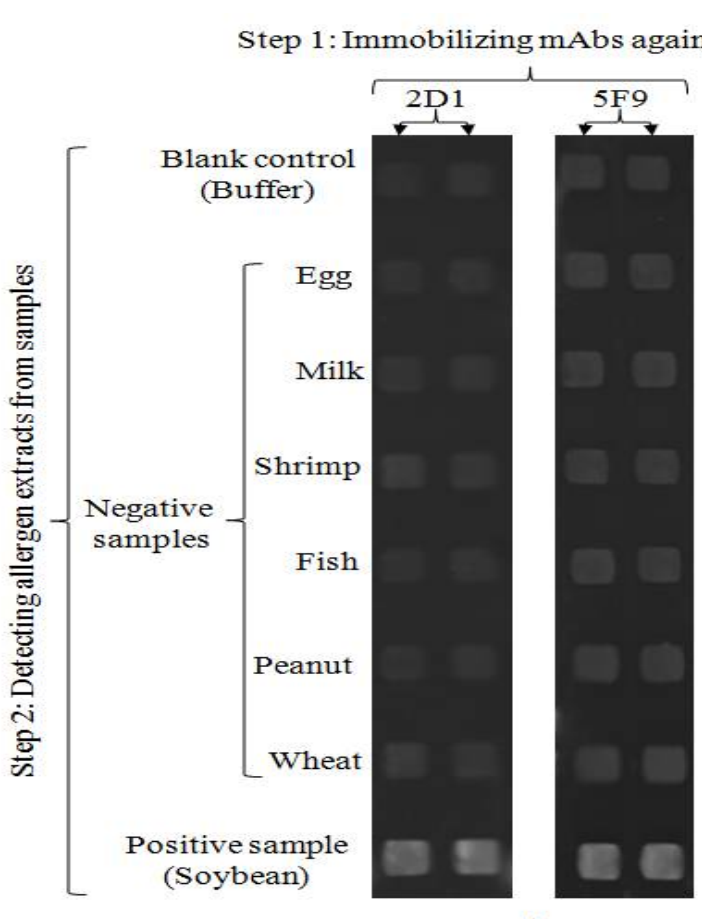

A

Gray-scale value of corresponding areas in left image
\begin{tabular}{|c|c|c|c|}
\hline 54.1 & 55.3 & 66.1 & 65.1 \\
\hline 55.9 & 56.7 & 66.4 & 66.8 \\
\hline 58.1 & 58.2 & 67.3 & 67.7 \\
\hline 57.3 & 58.1 & 67.9 & 67.4 \\
\hline 56.9 & 56.5 & 67.2 & 67.4 \\
\hline 55.1 & 55.7 & 67.9 & 68.3 \\
\hline 58.9 & 57.8 & 67.1 & 68.1 \\
\hline 105.7 & 109.9 & 122.7 & 119.8 \\
\hline
\end{tabular}

B

Figure 1: Qualitative detection of P34 with the biochips method. Gray scale image of the different food allergens detected $(A)$, and gray scale values corresponding to the gray scale images indicated in $A(B)$. 
5F9) could be measured with Ellipsometric Imaging Expert System. These results are indicated in Figure 1B and show that the mAbs (interacting with P34) have greater binding capacities for soybean allergen extracts than the other food allergens analyzed $(p<0.05)$.

\section{Sensitivity and stability of the detection}

Five serially diluted concentrations of the P34 standard sample were used to confirm the sensitivity (Figure 2). The results indicated that changes in signal strength varied directly with changes in concentration of the P34 allergen (1$25 \mathrm{mg} / \mathrm{L})$. The sensitivity of detection for P34 levels for 2D1 and 5F9 was $1.0 \mathrm{mg} / \mathrm{L}$. The gray scale values of the blank control were $56.0 \pm 1.1$ and $66.2 \pm 0.9$, respectively, while the values of the negative control (milk) were $56.8 \pm 1.8$ and $66.7 \pm 2.7$, i.e., values for $2 \mathrm{D} 1$ and $5 \mathrm{~F} 9$ were about 1.4 and $0.75 \%$, respectively, higher than those of the blank control. The values for the positive sample $(1.0 \mathrm{mg} / \mathrm{L} \mathrm{P} 34)$ were $62.1 \pm 1.1$ and $71.5 \pm 1.3$, about 10.9 and $8.0 \%$ higher than that of the blank controls. These values were approximately 9.3 and $7.2 \%$, respectively, higher than those of the negative controls. This indicates that the sensitivity of this assay reached up to $1.0 \mathrm{mg} / \mathrm{L}$.

\section{Detection of P34 allergen in commercial foods}

Six different commercial foods were analyzed to further investigate the accuracy and reliability of biochips. The results indicated that signal strengths of pineapple cake, chocolate biscuits, cream cake, and soybean milk powder were brighter than those measured for blank control (PBST) and negative control (Graham bread), while the signal strength of cereal bar was almost the same as those of the control groups (Figure 3A). The signal strength was also represented by the gray scale (Figure 3B). Commercial foods (pineapple cake, chocolate biscuits, cream cake, and soybean milk powder) had significant variations in gray scale values $(p<0.05)$, unlike cereal bar. To confirm the accuracy of this assay, these commercial foods were also analyzed by ELISA and, in all cases, identical results were obtained by both methods (Figure 3 C). ELISA results for the cereal bar and graham bread were similar to those for the blank control $(0 \mathrm{mg} / \mathrm{kg}$ soybean protein). The optical density (OD) values of other commercial foods were higher than those of the control groups $(p<0.05)$. These observations confirm that the results obtained by biochip were in agreement with those obtained using ELISA.

\section{DISCUSSION}

Nowadays, there are few available data describing the threshold dose of soybean allergens that brings about allergic reactions. In a recent study on the clinical manifestations of soybean allergy in Europe, soybean-allergic individuals underwent a double-blind placebo-

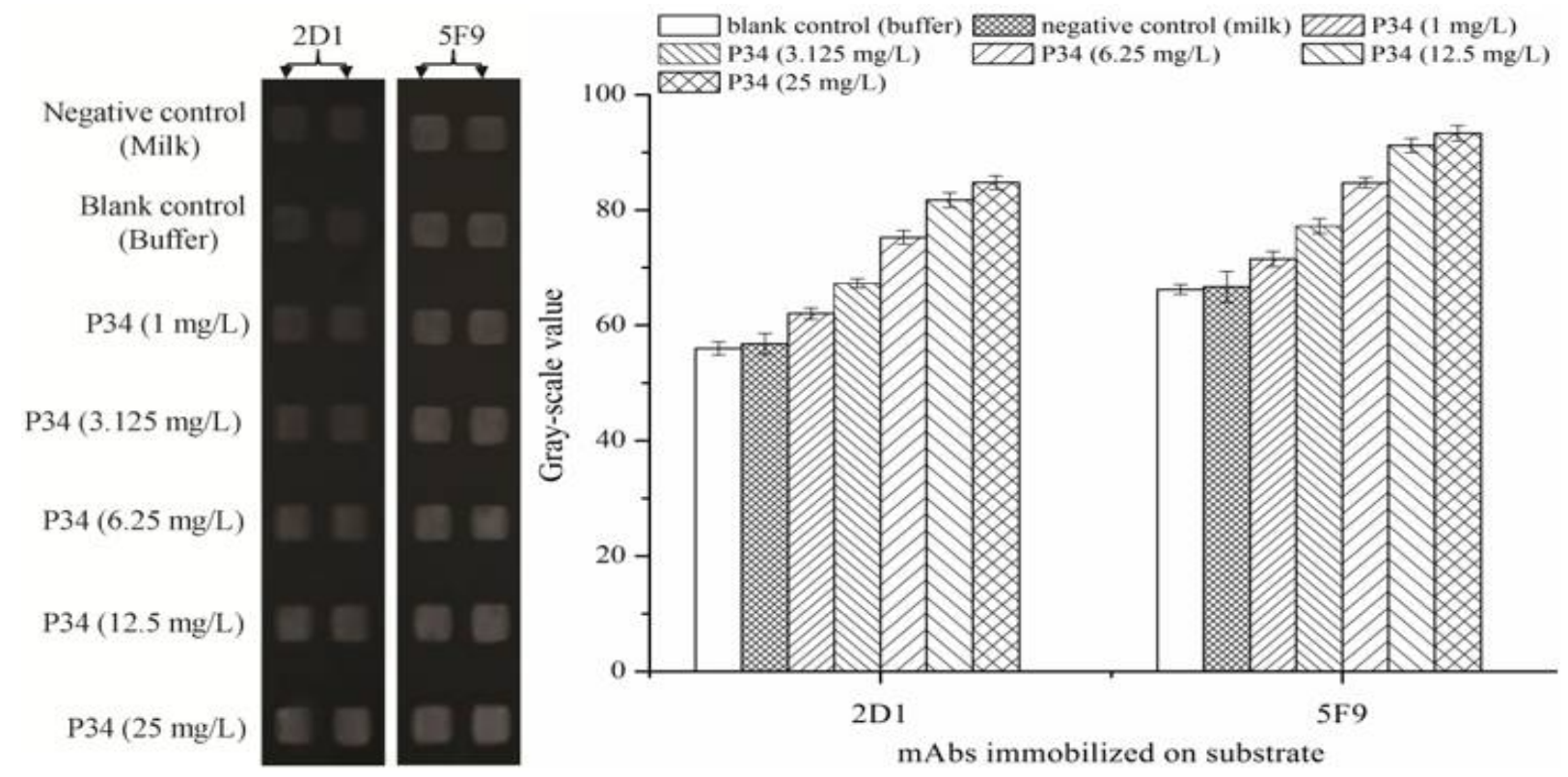

A

B

Figure 2: Sensitivity of biochips in detecting P34 with mAbs (2D1 and 5F9) as ligands. Gray scale images of a serial dilution of P34 detected $(A)$, and average gray scale values corresponding to the gray scale images indicated in $\mathrm{A}$ (for two duplicate units) (B) 


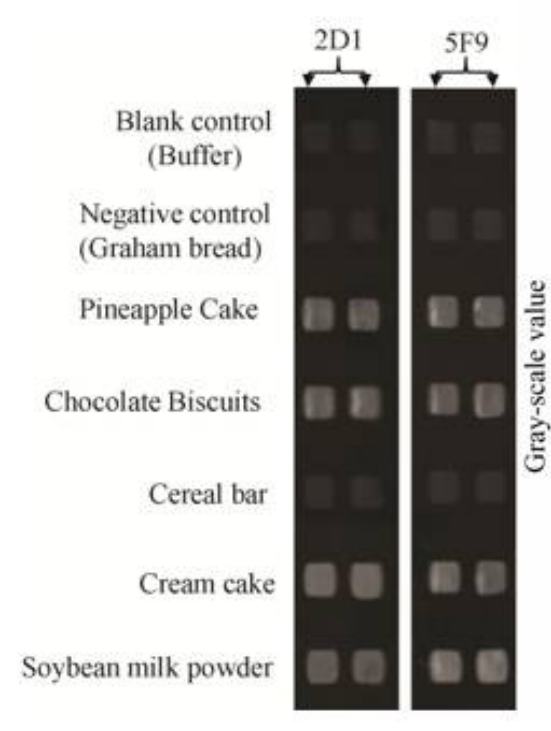

A

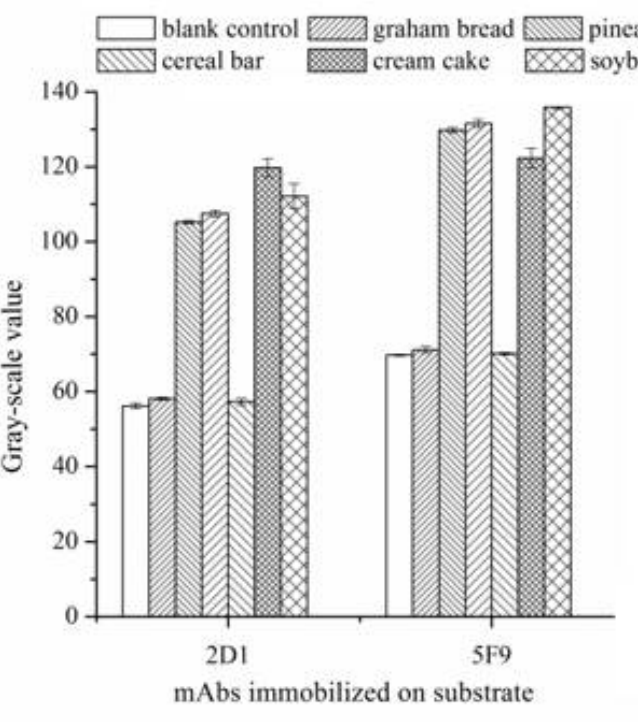

B

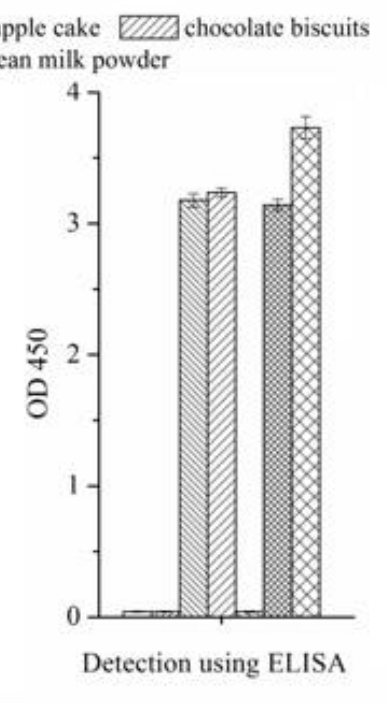

$\mathrm{C}$

Figure 3: Detection of P34 in commercial food samples with the biochips method. Gray scale images of P34 detected by biochips in commercial samples (A); average gray scale values corresponding to the gray scale images (for two duplicate units) (B) and ELISA for the detection of commercial foods (C)

controlled food challenge test [16]. The results of that study showed that cumulative threshold doses which elicited soybean-allergic varied from $10 \mathrm{mg}$ to $50 \mathrm{~g}$ for subjective symptoms, and from $454 \mathrm{mg}$ to $50 \mathrm{~g}$ for objective symptoms. In another study in America, 15 out of 53 (28\%) soybean-allergic children with atopic dermatitis reacted to less than $0.5 \mathrm{~g}$ of soybean flour (equivalent to approximately $41 \mathrm{mg}$ of soy protein) [17].

The present study confirms that the results of qualitative detection of P34 allergen are in agreement with the results obtained by ELISA [18]. This is indicates that the antibodies used in the present study were capable of specific detection of the P34 allergen. Moreover, the detection sensitivity obtained is sufficient to meet the demands of practical application. Practical applicability of the biochip method was also tested by analysis of six different food products, and the results indicated that the soybean ingredients in food products could be detected using P34 as the target protein. These results indicate clearly that this technique has both labelfree and high throughput characteristics, which shorten analysis time, exhibit high specificity and sensitivity, and may be used as an alternative or complementary method to extant immunochemical and DNA-based methods.

\section{CONCLUSION}

A label-free, rapid and specific biochip has been presented and validated for detection and identification of the major soybean allergen Gly
$\mathrm{mBd} 30 \mathrm{~K}$ (P34). The results demonstrate that this assay can be used for the sensitive and qualitative detection of P34 allergen through a simple and rapid procedure. The method has potential for application in direct detection of multiple food allergens.

\section{DECLARATIONS}

\section{Acknowledgement}

This work was supported by Natural Science Foundation of Jiangsu Province (no. BK20140722), Fundamental Research Funds for the Central Universities (no. KJQN201646) and National Natural Science Foundation of People's Republic of China (no. 31501395).

\section{Conflict of Interest}

No conflict of interest associated with this work.

\section{Contribution of Authors}

The authors declare that this work was done by the authors named in this article and all liabilities pertaining to claims relating to the content of this article will be borne by them.

\section{Open Access}

This is an Open Access article that uses a funding model which does not charge readers or their institutions for access and distributed under the terms of the Creative Commons Attribution 
License (http://creativecommons.org/licenses/by/ 4.0) and the Budapest Open Access Initiative (http://www.budapestopenaccessinitiative.org/rea d), which permit unrestricted use, distribution, and reproduction in any medium, provided the original work is properly credited.

\section{REFERENCES}

1. L'Hocine L, Boye Jl. Allergenicity of soybean: new developments in identification of allergenic proteins, cross-reactivities and hypoallergenization technologies. Crit Rev Food Sci Nutr 2007; 47(2): 127-143.

2. Sicherer SH, Sampson HA, Burks AW. Peanut and soy allergy: a clinical and therapeutic dilemma. Allergy 2000; 55(6): 515-521.

3. Ogawa $T$, Samoto M, Takahashi, K. Soybean allergens and hypoallergenic soybean products. J Nutr Sci Vitaminol 2000; 46(6): 271-279.

4. Helm R, Cockrell G, Herman E, Burks A, Sampson $H$, Bannon G. Cellular and molecular characterization of a major soybean allergen. Int Arch Allergy Immunol. 1998; 117(1): 29-37.

5. Ogawa T, Tsuji H, Bando N, Kitamura K, Zhu YL, Hirano $H$, Nishikawa $K$. Identification of the soybean allergenic protein, Gly $m$ Bd 30K, with the soybean seed 34-kDa oil-body-associated protein. Biosci Biotechnol Biochem 1993; 57(6): 1030-1033.

6. Kerbach S, Alldrick AJ, Crevel RWR, Dömötör $L$, DunnGalvin A, Mills ENC, Pfaff S, Poms RE, Popping B, Tömösközi S. Managing food allergens in the food supply chain-viewed from different stakeholder perspectives Qual Assur Saf Crop. 2009; 1(1): 50-60.

7. Rona $R$, Keil $T$, Summers $C$, Gislason D, Zuidmeer $L$, Sodergren E, Sigurdardottir S, Lindner T, Goldhahn K, Dahlstrom J. The prevalence of food allergy: a metaanalysis. J Allergy Clin Immunol 2007; 120(3): 638-646.

8. Woollama JA, Snydera PG, Rosta MC. Variable angle spectroscopic ellipsometry: a non-destructive characterization technique for ultrathin and multilayer materials. Thin Solid Films 1988; 166(1): 317-323.

9. Zhan $Q$, Leger JR. High-resolution imaging ellipsometer. Appl Opt 2002; 41(22): 4443-4450.

10. Niu Y, Zhuang J, Liu L, Yan XY, Jin G. Two kinds of antiricin antibody and ricin interaction evaluated by biosensor based on imaging ellipsometry. Thin Solid Films 2011; 519(9): 2768-2771.

11. Qi C, Lin Y, Feng J, Wang ZH, Zhu CF, Meng YH, Yan $X Y$, Wan LJ, Jin G. Phage M13KO7 detection with biosensor based on imaging ellipsometry and AFM microscopic confirmation. Virus Res 2009; 140(1-2): 7984.

12. Zhang HG, Qi C, Wang ZH, Jin G, Xiu RJ. Evaluation of a new CA15-3 protein assay method: optical protein-chip system for clinical application. Clin Chem 2005; 51(6): 1038-1040.

13. Wang $Z H$, Jin $G$. Visualization of the interaction between IL-6 and IL-6R by imaging ellipsometry. Chin J Biotechol 2002; 18(1): 99-101.

14. Qiao BS. Experimental Technique of Allergy, 2nd edn. Beijing: Peking Union Medical College Press; 2002.

15. Wang $Z H$, Meng $Y H$, Ying $P Q$, Qi $C$, Jin G. A label-free protein microfluidic array for parallel immunoassays. Electrophoresis 2006; 27(20): 4078-4085.

16. Ballmer-Weber BK, Holzhauser T, Scibilia J, Mittag D, Zisa $G$, Ortolani $C$, Oesterballe $M$, Poulsen $L K$, Vieths $S$, Bindslev-Jensen $C$. Clinical characteristics of soybean allergy in Europe: a double-blind, placebocontrolled food challenge study. J Allergy Clin Immunol 2007; 119(6): 1489-1496.

17. Sicherer SH, Morrow EH, Sampson HA. Dose-response in double-blind, placebo-controlled oral food challenges in children with atopic dermatitis. J Allergy Clin Immunol 2000; 105(3): 582-586.

18. Zou J, Liu ZG. Preparation and Application of Monoclonal Antibodies against Allergen Gly $m$ Bd 30K. Soyb Sci 2011; 30(5): 723-726. 